\title{
Connected we stand: A network perspective on global food security
}

\author{
Martina SARTORI \\ University of Trento - School of International Studies \\ Center for Research on Energy and Environmental Economics and Policy - IEFE, Bocconi University, \\ Milan, Italy. \\ E-mail: martina.sartori@lett.unitn.it
}

\author{
Stefano SCHIAVO \\ (Corresponding author) \\ University of Trento - School of International Studies and Department of Economics and \\ Management \\ Observatoire Français des Conjonctures Économiques - DRIC. \\ E-mail: $\underline{\text { stefano.schiavo@unitn.it }}$
}

\begin{abstract}
We analyze the link between virtual water trade, that is, the flow of water embodied in the international trade of agricultural goods, and vulnerability to external shocks from the vantage point of network analysis. While a large body of work has shown that virtual water trade can enhance water saving on a global scale, being especially beneficial to arid countries, there are increasing concerns that openness makes countries more dependent on foreign food suppliers and, in this way, more prone to external shocks. Our evidence reveals that the increased globalization witnessed in the last three decades is not associated with the increased frequency of adverse shocks (in food production). Furthermore, building on recent advances in network analysis that connect the stability of a complex system to its topological features, we find that the world is more interconnected, but not necessarily less stable.
\end{abstract}

Keywords: virtual water; international trade; vulnerability; complex networks; agricultural production shocks

JEL codes: F14, F18, Q25, Q56

\section{Acknowledgements}

Financial support received through the project "The global virtual-water network: social, economic, and environmental implications" (FIRB - RBFR12BA3Y) funded by the Italian Ministry of Education, University and Research (MIUR) is gratefully acknowledged. The authors thank Francesco Laio and Stefania Tamea for providing the data on virtual water trade, Andrea Fracasso for insightful comments on an earlier draft of the paper, two anonymous referees and the Journal Editor for their suggestions and valuable inputs. 


\section{Introduction}

This paper investigates whether the globalization of food trade has made the world more vulnerable to shocks and, as a result, whether there is a trade-off between stability and openness. To do so we exploit the insights provided by network analysis: we study the structural features of the web of bilateral trade flows in agricultural goods -and the associated flows of virtual water- to ascertain whether they have evolved in a way that makes the world system more (or less) prone to large disruptions. In our endeavor, we relate to several streams of the existing literature, and interweave them to provide novel and original insights on the relationship between international trade and food security.

The idea of measuring the water 'embodied' in goods, and 'virtually' traded from one country to another when goods are sold across borders, has been introduced by Allan (1993). In his seminal study, Allan describes virtual water (VW) trade as a market-mediated mechanism that enables water-scarce regions to cope with water scarcity (and food security) over the past few decades. Subsequently, VW flows among countries engaged in trade have been estimated and widely studied (see, for instance, Hoekstra and Hung 2002; Oki and Kanae 2004; Hoekstra and Chapagain 2008; Roson and Sartori 2015; or Antonelli and Sartori 2015 for a recent review of the literature).

In the last decade, a number of studies have applied complex network analysis to study the features of VW trade as a global network. This has led to the unveiling of the main topological characteristics of the VW network (Konar et al. 2011; Tamea et al. 2013), highlighting clues of small-world behavior (Shutters and Muneepeerakul 2012), the occurrence of hubs and rich-club effects (Suweis et al. 2011), and the existence of a community structure (D'Odorico et al. 2012). In Carr et al. (2012), Dalin et al. (2012), and D'Odorico et al. (2012), the temporal evolution of the virtual water network is also analyzed, showing the progressive intensification of VW exchanges and the geography of these variations.

We contribute to this literature by linking the topological features of the global network of VW trade to the resilience of the world system to shocks. In fact, the relationship between network topology and shock propagation has received considerable attention in the last few years, especially since the recent financial crisis has forcefully highlighted the importance of the issue. A series of recent contributions by Acemoglu et al. (2012, 2013, 2015) examine the interplay between idiosyncratic shocks to individual actors in a network and the probability of large cascade effects that could threaten the stability of the system. They show that the propagation of shocks depends on the presence of relatively few dominant sectors. This feature, captured by the presence of heavy (or fat) tails in the distributions of some key network indicators, imply that shocks hitting central players will quickly propagate to the rest of the economy, with the complex web of linkages magnifying (rather than dampening) their effect.

Our analysis starts by looking at the distribution and frequency of large shocks in agricultural output over the last three decades, in order to see whether, due to climate change, population growth or other global trends, these shocks have become more common over time. Second, since the structural features of the international trade network connecting countries plays an important role in the transmission of shocks (Acemoglu et al. 2012), we study both the topology and the evolution of the network of trade in agricultural goods (translated into VW flows). We find no evidence of an increased frequency of adverse shocks in food production; moreover, while the globalization of food trade has made the VW network more interconnected over time, its structural characteristics have not evolved in a way that enhance systemic fragility.

Our conclusions therefore contribute, from a novel perspective, to the debate on the relationship between food sovereignty, food security, and trade openness (Montalbano 2011; Burnett and Murphy 2014), that is characterized by conflicting views. For instance, Headey (2011) suggests that trade integration may increase a country's exposition to external disturbances, and this is especially true in the case of small countries. However, Paarlberg (2000) argues that transitory food insecurity in poor countries are not induced by changing conditions in international grain markets, rather by internal 
conflicts and natural disasters, as the reliance of these countries on grain imports is usually low. Furthermore, Allouche (2011) points out that, when water and land resources are scarce, food imports represent the main channel though which countries fulfill their food needs, so that global trade enhances food and water security. For instance, Tanaka and Hosoe (2011) find that protection of the domestic rice market harms, rather than ensures, Japan's national food security. Matthews (2014) claims that an open and predictable trading system plays an essential role in promoting global food security by making the system more efficient and more responsive to shocks. Similar conclusions are reached also by Huang et al. (2011) and Rutten et al. (2013). The former argue that international trade plays an important role in compensating climate-induced changes in productivity; the latter investigate the effects of trade policy responses to a negative supply shock (in the wheat market) and claim that liberalizing trade contributes to food security.

To the best of our knowledge, ours is the first study that applies network analysis and investigates the structural features of VW trade to address the potential trade-off between trade openness and food security. The paper is structured as follows: the next section describes the data used and defines the basic network measures employed in the analysis; Section 3 illustrates the results of the empirical investigation, while the final section discusses the policy implications and draws some concluding remarks.

\section{Data and methodology}

\subsection{Virtual water and virtual water trade}

The VW content of (agricultural) goods is the volume of water that is used to produce them. It depends on several aspects, such as the place and time of production, the technology used and water use efficiency. VW trade refers to the exchange of virtual water implied by international trade, with most authors focusing on agricultural goods, as we also do in this paper.

When a good is exported (imported), its VW content is implicitly exported (imported) as well. Any trade flow can be translated in its VW equivalent by using country-specific measures of the VW content of each product. In this framework, the concept of VW becomes a useful indicator for the study of virtual water exchanges underlying food trade and represents a way to link international trade and water resources. A VW flow is obtained by multiplying the estimated (country-specific) VW content by the volume of trade in agricultural goods registered. Food production and international trade data for a total of 309 crops and animal products for the period 1986-2010 are obtained from the FAOSTAT database, while Mekonnen and Hoekstra (2011) provide estimates of the country-specific VW content of various goods. ${ }^{1}$ The total number of countries considered is 253 ; since the number of active countries varies in time due to geo-political changes (e.g. they are 208 in 1986 and 211 in 2010), inactive countries in a given year were simply removed from the analysis. For each single year, the global matrix of aggregate VW trade is obtained by summing the flows relative to 309 individual crops for which we have information.

\subsection{Network analysis: basic concepts}

The global VW trade system is populated by $N$ nodes (countries), connected by links that represent VW flows. The network is represented by a square matrix $W_{N}$ (dimensions $N \times N$ ), where exporters are

\footnotetext{
${ }^{1}$ For a detailed description of the way in which the VW content of the trade flows was computed, we refer to Carr et al. (2012, 2013) and Tamea et al. (2014). We owe a debt of gratitude to these authors, who shared the data on virtual water trade flows. Appendix B reports the list of countries and FAO products considered in computing the virtual water flows. Dalin et al. (2012) and Konar et al. (2011) use a different method, namely the $\mathrm{H} 08$ global hydrological model, to determine the virtual water content of different goods.
} 
on rows and importers on columns. Each cell $w_{i j}$ captures the VW flow from country $i$ to country $j$, with $w_{i i}=0$. The sum over row $i$ is the total amount of VW exports of country $i$, while the sum over column $j$ is the total amount of VW imports of country $j$. The international VW trade gives rise to a weighted and directed network, in which the link direction goes from the exporting to the importing country, and the link of each weight is given by the volume of virtual water flowing between any country pair. From this directed and weighted network one can derive a binary (unweighted) version by disregarding the information on link weights and simply accounting for the presence/absence of a trade connection. In this case the $N \times N$ matrix representing the network is called an adjacency matrix $A_{N}$ and its generic element $a_{i j}$ is either one or zero depending on whether countries $i$ ad $j$ are connected or not.

The structural features of a network (its topology) are described through several indexes. One of the first ways to characterize a network is to count its players (nodes) and links, and to look at its density, given by the number of active links over their total possible number (if all nodes were connected with every other node).

Node degree $\left(k_{i}\right)$, which measures the number of contacts maintained by each node, here translated as the number of trade partners of a country, is defined as $k_{i}=\sum_{j} a_{i j}$, where $a_{i j}$ is the element of the binary adjacency matrix $A_{N}$. In the case of directed networks, the indegree counts the number of edges directed to a certain node, while the outdegree represents the number of outgoing links. Applied to the VW trade network, the former is the number of import flows, while the latter counts the number of destinations served.

The weighted counterpart to degree is given by node strength $\left(s_{i}\right)$, i.e. is the sum of all the link weights $w_{i j}$ of each node (representing the total VW imports or exports), where $s_{i}^{i n}=\sum_{j} w_{j i}$ is the indegree (import) strength, while $s_{i}^{\text {out }}=\sum_{j} w_{i j}$ is the outdegree (export) strength. In the case of VW network, link weights are virtual water flows.

Another important feature of a network is its assortativity, i.e. the tendency of highly connected nodes to be link to other high-degree nodes. The assortativity index $r$ for network $G$, computed following Newman (2003), is $r=\sum_{i j \in G}\left(k_{i}-\bar{k}\right)\left(k_{j}-\bar{k}\right) / \sum_{i \in G}\left(k_{i}-\bar{k}\right)^{2}$, where $k_{i}$ is the degree of node $i$ and $\bar{k}$ is the average degree in the network. The index $r$ ranges between -1 and 1 and can be thought of as a correlation coefficient between the degree of a node and that of its partners.

A further element to evaluate the structure of the networks is provided by the clustering coefficient $c_{i}$, which represents the tendency of nodes to form tightly connected groups. Formally, $c_{i}=2 e_{i} / k_{i}\left(k_{i}-1\right)$, where $e_{i}$ is the number of links between the neighbors of node $i$ and $k_{i}\left(k_{i}\right) / 2$ is the maximum possible number of links existing between the $k_{i}$ neighbors of $i$ (Boguna and Pastor-Satorras 2003). In other words, $c_{i}$ counts the number of closed triangles formed in the neighborhood of node $i$. This value measures the local cohesiveness of the network and higher values indicate that the neighbors of $i$ are themselves connected. The clustering coefficient for the whole network is then given by the average of each node $i$ s coefficient.

Centrality is another popular network index, which is meant to capture, for each node, its position within the network and its relative importance. Node degree is the most basic measure of local centrality, as it only looks at the immediate neighborhood of each node. Many other centrality measures exist, each capturing a specific feature of the network and what flows in it. Here we use eigenvector centrality, which quantifies the influence of a node in the network and is defined recursively as the sum of centrality of all its neighbors (Bonacich 1972). It assigns relative scores to each node, based on the concept that connections to high-scoring nodes contribute more to the score of the node in question than links to low-scoring nodes. Eigenvector centrality appears to be more suitable in the case of the VW network, where the role of a country is positively related to its own position and that of the countries it is connected to, in terms of the volume of VW that it exchanges. Starting from the centrality of each node, we can compute a centralization index, which measures how tightly the graph is organized around its most central point. To do this, we compare the actual VW network with a start 
graph, i.e. a structure where a single central node exists, connected to all other nodes, which in turn are not connected among them. Centralization is the ratio of the sum of the difference between the centrality of each node relative to the most central player to the maximum possible value of such a sum (which occurs in a star graph). The index is computed as $C I=\sum_{i}\left|b_{\text {MAX }}-b_{i}\right| / \sum_{i}\left|\chi_{\text {MAX }}-\chi_{i}\right|$, where $b_{M A X}$ and $b_{i}$ are the centrality values of the most central node and the $i$-th node in the observed graph, while $\chi_{M A X}$ and $\chi_{i}$ are the corresponding values in a star graph composed of as many nodes as the observed network. The centralization index $C I$ ranges between 0 and 1, where 0 indicates a balanced graph in which all the nodes have the same centrality and 1 implies a star graph with a single node as its center.

\section{Empirical analysis}

The research question that underlies this paper is whether the globalization of food trade, has made the world more vulnerable to shocks and, as a result, whether there is an actual trade-off between stability and openness. It is worth mentioning here that we take a systemic perspective, looking at the world as a whole rather than at any specific country. While we think network analysis could be very useful to define country-specific measures of vulnerability, this venture goes beyond the scope of the paper and represents an interesting venue for further research. ${ }^{3}$

In Section 3.1 we examine the frequency of supply shocks that might be transmitted across borders via international trade, checking whether extreme events have become more likely over time due for instance to climate change of increased pressure on natural resources from population growth. Second, we investigate the topological properties of the VW trade network to determine whether its structure and evolution may give rise to a more fragile world system (Section 3.2).

In fact, the global VW trade system, like many other global networks, is both interconnected and interdependent. These features may result in small, local shocks that have a strong systemic effect, potentially threatening the stability of the network, due to cascading failures transmitting across the network's ties (see, for instance, Carlson and Doyle 2002 or Doyle et al. 2005). In the last few years, partly as a consequence of the recent financial crisis, this notion has percolated into economic analysis, and the relationship between network structure and stability has been attracting a large amount of attention, especially in financial economics. ${ }^{4}$ Generally speaking, greater connectivity reduces the likelihood of system failures because shocks are more easily dissipated. However, the relationship between network topology and stability is highly non-linear and marked by the existence of extreme behaviors and tipping points (Haldane and May 2011; Acemoglu et al. 2015). Several studies link the possible emergence of contagion with the degree of heterogeneity in the network, which can refer either to nodes' intrinsic characteristics (such as size, see Iori at al. 2006) or to nodes' connectivity (Caccioli et al. 2012). Indeed, when the network is not homogeneous, the positive effect of greater density on diversification is counterbalanced by the fragility associated with the presence of very central (and therefore critical) players (Battiston et al. 2012). Acemoglu et al. (2015) provide a unifying framework that reconciles seemingly contradictory results in the field, and show under which conditions the structure of the network is conducive to cascades that threaten the stability of the system. The key intuition is that looking at the local centrality measures and the existence of very central nodes is not sufficient, but one should also investigate the higher-order features of the network.

\footnotetext{
${ }^{2}$ For an interesting analysis of country-specific food security in presence of external supply risks, see the work by Hubbard and Hubbard (2013) on the UK.

${ }^{3}$ In line with our global perspective, the meaning of vulnerability that we use throughout the paper concerns systemic stability. For a discussion on alternative definitions of vulnerability in the context of food security see Dilley and Boudreau (2001).

${ }^{4}$ For an overview of the literature on financial networks, see Allen and Babus (2009) or Bougheas and Kirman (2014).
} 


\subsection{Supply shocks}

We start our investigation by looking at shocks to agricultural output. We study both their distribution, to gauge the likelihood of extreme events, and its evolution over time, to see whether large shocks have become more frequent over time.

Fluctuations in output volumes may have different origins, like changes in factor productivity induced by climate and technological variations, demand-driven changes, and the like. All of them, trough different channels, may affect international trade, which in turn modifies VW flows among countries.

Data on agricultural production (ton/yr) are available from 1961 to 2012. By fitting a linear trend to the data, we compute the yearly deviation of the empirical data from the values predicted by the trend. The use of a linear trend allows us to take into account variations in productivity or other long-run changes. As food crises are associated with drops in output, not over-abundance, we only consider those cases in which actual agricultural output falls short of the expected value of production. ${ }^{5}$

Our analysis aims at detecting the likelihood of large negative shocks in agricultural production or, in other words, the presence of heavy (or fat) tails in the distribution of shocks. These in turn would suggest that the probability of extreme events (e.g. a sizable output loss) is larger than it would be under the Normal or another thin-tailed distribution. ${ }^{6}$ The extent to which the tails of the distribution have become heavier over time is also investigated.

We calculate two indexes of tail heaviness commonly used in the literature (Table 1): the first is the percentage of observations that stay out of the interval "mean \pm double standard deviation", while the second is the Obesity Index proposed by Cooke et al. (2014). ${ }^{7}$ The latter is computed as $O b(X)=$ $P\left(X_{1}+X_{4}>X_{2}+X_{3} \mid X_{1} \leq X_{2} \leq X_{3} \leq X_{4}\right)$, and is based on the heuristic that, in the case of heavy-tailed distributions, larger observations lie further apart than smaller observations. $\left\{X_{1}, \ldots, X_{4}\right\}$ are independent and identically distributed values randomly sampled from the data. ${ }^{8}$ In our application, the index is based on 1,000 random samples of 4 observations.

Table 1. Indexes of tail heaviness.

\begin{tabular}{ccc}
\hline Year & $\begin{array}{c}\text { \% of obs out } \\
\text { of interval }\end{array}$ & $\begin{array}{c}\text { Obesity } \\
\text { Index }\end{array}$ \\
\hline $\mathbf{1 9 8 6}$ & 1 & 0.91 \\
$\mathbf{1 9 9 0}$ & 1 & 0.91 \\
$\mathbf{1 9 9 5}$ & 2 & 0.89 \\
$\mathbf{2 0 0 0}$ & 5 & 0.89 \\
$\mathbf{2 0 0 5}$ & 3 & 0.90 \\
$\mathbf{2 0 1 0}$ & 2 & 0.88 \\
\hline
\end{tabular}

\footnotetext{
${ }^{5}$ We are aware that positive output shocks, as well as negative ones, might affect world prices and, though this channel, impact on farmers' income. This kind of analysis is however beyond the scope of the paper.

${ }^{6}$ Throughout the paper, we use heavy or fat tails interchangeably. In the presence of a thin-tailed probability distribution, the upper tail declines to zero exponentially or faster. Such a distribution has a moment generating function, and all moments exist. A normal or a gamma distribution is an example of the thin-tailed probability distribution function, as is any distribution with finite supports, like a uniform distribution or a discrete-point finite distribution. On the contrary, a fat-tailed distribution falls to zero much more slowly. The standard example of a fat-tailed probability distribution function is the power law or Pareto distribution, although a Student- $t$ or invertedgamma distribution is also fat-tailed.

${ }^{7}$ The simple heuristic (mean \pm 2 times standard deviation) computes the percentage of values that lie within a band around the mean in a normal distribution with a width of two standard deviations, approximately $95 \%$ of the observations. It is often employed as a quick and simple test for outliers, in presence of a Gaussian population, and as a normality test when the population is potentially not normal (as in this case). Extreme values of a distribution are more probable than in the case of a normal distribution for higher percentages of this heuristic.

${ }^{8}$ The Obesity Index is the probability that the sum of the largest and the smallest of four observations is larger than the sum of the other two observations; it captures the idea that larger values are further apart. It assumes value 0.5 and 0.75 in case of normal and exponential distributions, respectively. When the distribution has heavy tails, this index lies in the range [0.80; 1]. Decreasing values suggest a reduction in tail heaviness over time.
} 
Table 1 shows that the percentage of outlier values lying more than two standard deviations away from the mean range is low, between 1\% (in 1986 and 1990) and 5\% (in 2000). In these cases, deviations are mostly associated with some of the largest agricultural producers in the world, namely China, Russia, and India. These deviations are never lower than $-15 \%$ of the predicted values, with only one exception (in the year 2010, the observed value for Russia is $24 \%$ lower than the predicted one). ${ }^{9}$ The values of the Obesity Index are larger than the expected value for an exponential distribution (0.75) and close to those implied by a Zipf's law (0.87), ranging between 0.88 and 0.91 , but decrease over time. Although the procedure proposed by Clauset et al. (2009) to detect power-law behavior in the data does not provide us with clear-cut evidence, the tails of the distributions are likely to be heavy. Yet the likelihood of extreme events diminishes slightly over the period analyzed.

A further method to look for fat tails in a distribution is to compare the plot of the mean excess function (MEF) of the data with the MEF plot obtained through aggregation of the original data set by $m$ (as suggested by Cooke et al. 2014). The mean excess function of a random variable $X$ gives the expected excess of the random variable over a certain threshold $u$, given that the random variable is larger than the threshold. It is defined as $e(u)=E(X-u \mid X>u)$. Following the procedure by Cooke et al. (2014), we first divide the data set randomly into groups of size $m=2$ and $m=4$ and then we sum each of these $m$ values. ${ }^{10}$ Aggregating the sample does not have much effect on the mean excess plot of data coming from heavy-tailed distributions, while this is no longer valid for data coming from thintailed distributions. That is, in presence of heavy tails, the two mean excess plots should be very similar. As an example, Figure 1 plots the MEFs for the distribution for the years 1995 (left panel) and 2010 (right panel).

The qualitative result displayed in Figure 1 is the same for all the years in our sample. First of all, according to Burnecki and Weron (2008) and Ghosh and Resnick (2010), the upward-sloping shape followed by the MEF of the original data is consistent with the behavior expected for a Pareto distribution. Second, by tuning $m$, the MEF plot does not changes so much, being upward sloping and constant upon aggregation, suggesting that the data likely come from a heavy-tailed distribution. The likelihood of large output losses is bigger than one would expect under, say, a normal distribution of shocks. On the other hand, however, there is no evidence that large output losses have become more likely over time, at least in the last 25 years.
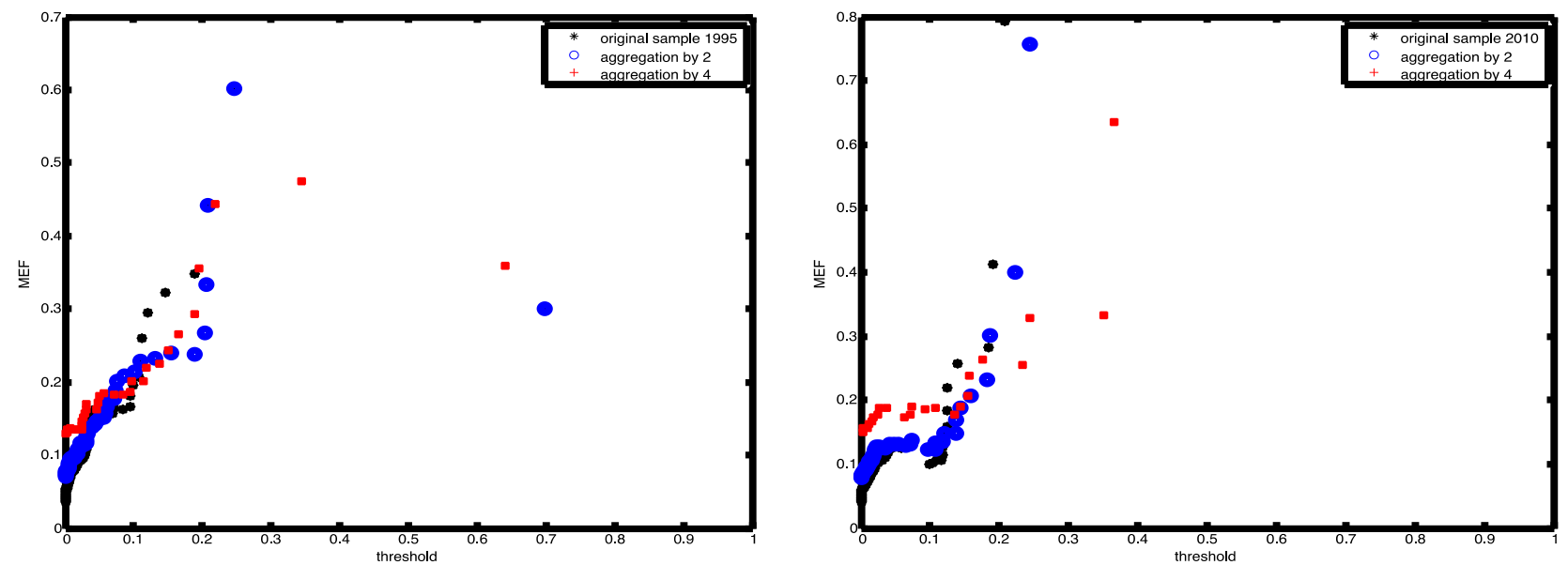

Figure 1. MEFs of the original sample and aggregated data set. Years 1995 (left panel) and 2010 (right panel).

\footnotetext{
9 1986: China -13\%; 1990: China -11\%; 1995: China -6\%; 2000: Russia -11\%; 2005: India -4\%; 2010: Russia $-24 \%$. As a percentage of global agricultural production, these lower output volumes are respectively: $-2.7 \%,-2.5 \%,-1.5 \%,-0.3 \%,-0.4 \%$, and $-0.6 \%$.

${ }^{10}$ The value of aggregation $m$ is arbitrarily chosen, proportionally to the size of the sample.
} 


\subsection{The topology of the virtual water network}

As mentioned in the Introduction, a recent body of research has shown that network structure may play a very important role in the transmission of shocks, both within a single economy and across borders. Hence, the second step of our analysis focuses on the topological properties of the global network of VW flows and its evolution over time.

Like many other global networks, the global VW trade system has the feature of being both interconnected and interdependent, with its pros and cons. On the one hand, the growing interconnectivity of global trade increases the robustness of the system to local crises. On the other hand, the increasing interdependency among climatic, demographic and economic networks could make the system prone to these crises (Allouche 2011), since cascading failures may transmit more or less quickly across the interconnected network. Assessing the vulnerability of the system to local crisis situations, geo-political crises, uncontrolled fluctuations in food prices and production volumes, is therefore worthy, since one may ask whether the benefits of being part of this network may be cancelled out by its intrinsic vulnerability. The recent contributions by Acemoglu et al. (2012, 2015) show that the propagation of the shocks at the macro level depends on some specific network characteristics, in particular the presence of relatively few dominant nodes, with several connections to many others. This characteristic implies that any shock affecting the central dominant nodes would propagate more easily to the rest of the network, affecting its stability.

Table 2 summarizes some of the topological features of the VW network, as described by the most commonly used network indicators. Over time, the number of active nodes increases, as well as the number of trade connections and the volume of water associated with global food trade, which more than doubles in 25 years, alongside a relatively stable maximum degree. The number of active nodes varies over time due to geo-political changes (mainly the dissolution of the Soviet Union), but remains otherwise stable. This is associated with a more than proportional increase in the number of links: network density (defined as the number of active links over the total number of possible connections) moves from $20 \%$ to $33 \%$, testifying to rising global trade. The maximum number of trade partners is always smaller than the number of players, meaning that none of the countries is connected with everybody else. There is a large difference between the average and the maximum number of partners, while the variability of node degree (the coefficient of variation) decreases over time.

Table 2. Topological features and descriptive statistics of the virtual water network.

\begin{tabular}{|c|c|c|c|c|c|c|c|c|c|c|c|c|c|}
\hline Year & $\begin{array}{l}\text { Active } \\
\text { Nodes }\end{array}$ & Links & Density & $\begin{array}{c}\text { Global } \\
\text { VW } \\
\text { Flow } \\
\left(10^{9} \mathrm{~m}^{3}\right)\end{array}$ & $\begin{array}{c}\text { Max } \\
\text { Str. }{ }^{\text {Out }} \\
\left.\text { (Str. }^{\text {In }}\right) \\
\left(10^{9} \mathrm{~m}^{3}\right)\end{array}$ & $\begin{array}{c}\text { Average } \\
\text { Strength } \\
\left(10^{9} \mathrm{~m}^{3}\right)\end{array}$ & $\begin{array}{l}\text { Max } \\
\text { Outd } \\
\text { (Ind). }\end{array}$ & $\begin{array}{c}\text { Max } \\
\text { Degree } \\
(\text { In+Out - } \\
\text { Bil })\end{array}$ & $\begin{array}{c}\text { Average } \\
\text { Degree } \\
* *\end{array}$ & $\begin{array}{c}\text { St. } \\
\text { Dev./ } \\
\text { Mean }\end{array}$ & Assort. & Clust. & $\begin{array}{l}\text { Centr } \\
\text { Index }\end{array}$ \\
\hline 1986 & 208 & 8,644 & $20.08 \%$ & $1,064.01$ & $\begin{array}{l}176.78 \\
(89.98)\end{array}$ & 5.12 & $\begin{array}{c}179 \\
(164)\end{array}$ & 184 & 55.30 & 0.85 & -0.43 & 0.80 & 0.16 \\
\hline 1990 & 205 & 8,643 & $20.67 \%$ & $1,182.88$ & $\begin{array}{l}198.11 \\
(98.49)\end{array}$ & 5.77 & $\begin{array}{c}181 \\
(161)\end{array}$ & 184 & 54.84 & 0.86 & -0.47 & 0.72 & 0.16 \\
\hline 1995 & $238^{*}$ & 11,605 & $20.57 \%$ & $1,431.71$ & $\begin{array}{c}239.44 \\
(100.10)\end{array}$ & 6.02 & $\begin{array}{c}204 \\
(178)\end{array}$ & 205 & 63.60 & 0.85 & -0.45 & 0.70 & 0.14 \\
\hline 2000 & 213 & 13,362 & $29.59 \%$ & $1,845.18$ & $\begin{array}{c}243.77 \\
(130.01)\end{array}$ & 8.66 & $\begin{array}{c}191 \\
(173)\end{array}$ & 195 & 81.44 & 0.64 & -0.35 & 0.65 & 0.11 \\
\hline 2005 & 211 & 14,432 & $32.57 \%$ & $2,355.30$ & $\begin{array}{c}243.61 \\
(179.10)\end{array}$ & 11.16 & $\begin{array}{c}198 \\
(171)\end{array}$ & 200 & 90.01 & 0.58 & -0.32 & 0.65 & 0.11 \\
\hline 2010 & 211 & 14,669 & $33.11 \%$ & $2,769.11$ & $\begin{array}{c}298.11 \\
(278.09)\end{array}$ & 13.12 & $\begin{array}{c}197 \\
(169)\end{array}$ & 202 & 90.63 & 0.59 & -0.33 & 0.64 & 0.10 \\
\hline
\end{tabular}

* This higher value is due to the dissolution of the Soviet Union

** Both the "average degree" indicator and the ratio "standard deviation over mean" indicator are computed on the degree distribution (the sum of in- and outdegree net of bilateral links)

The negative assortativity displayed by the VW network suggests a hub-and-spoke structure whereby low-connectivity countries establish links mainly with hubs, meaning countries with many partners. Similar results have already been found in the literature, both relative to the overall trade network (where it is, however, much more pronounced, see Fagiolo et al. 2010) and, more specifically, for VW 
trade (Konar et al. 2011). Similar to what happens for assortativity, which declines (in absolute value) over the years, the clustering coefficient also displays a marked reduction, moving from 0.80 to 0.64. This suggests that as the number of players increases, the relative importance of tightly connected cliques goes down.

The low and decreasing values of centralization are consistent with the idea that over time the system has become more balanced and homogeneous. Overall, the figures summarized in Table 2 suggest that from 1986 onward, the VW trade network has been evolving toward a less centralized and less disassortative network, with a decreasing number of clusters and a greater density. This qualitative picture is consistent with the results obtained in previous studies by Dalin et al. (2012) and Konar et al. (2011) and suggests that peripheral countries have increased their relative importance in terms of their number of trade partners, making the network more interconnected and interdependent, in other words more balanced. It is worth noting that this evolution could be identified just by looking at the increase in the volume of trade or in network density, but depends on the structural evolution of the network. In particular, as shown also in Figure 2 below, the data suggest that the network becomes more symmetric over time. ${ }^{11}$

To dig deeper into the possible role of network topology in the propagation of shocks, we consider whether the degree distribution features heavy tails, whereby the number of highly connected nodes is larger than one would expect. A fat-tailed distribution for node degree would imply the presence of a small core of very connected countries, featuring a much larger number of links than the rest of the nodes. Any shock affecting these central nodes would propagate easily to the rest of the network, and would not be completely compensated by shocks in the opposite direction.

In fact, several studies highlight that large heterogeneity in connectivity plays an important role in determining the fragility of a network (see for instance Caccioli et al. 2012). In particular, Acemoglu et al. (2012) suggest that when the degree distribution features heavy tails, systemic failures may result from cascade effects even in the presence of small original disturbances. We focus on the indegree distribution because the shocks that we are mainly interested in are supply-side disturbances, and also in the food policy discourse vulnerability is mainly associated with imports. ${ }^{12}$
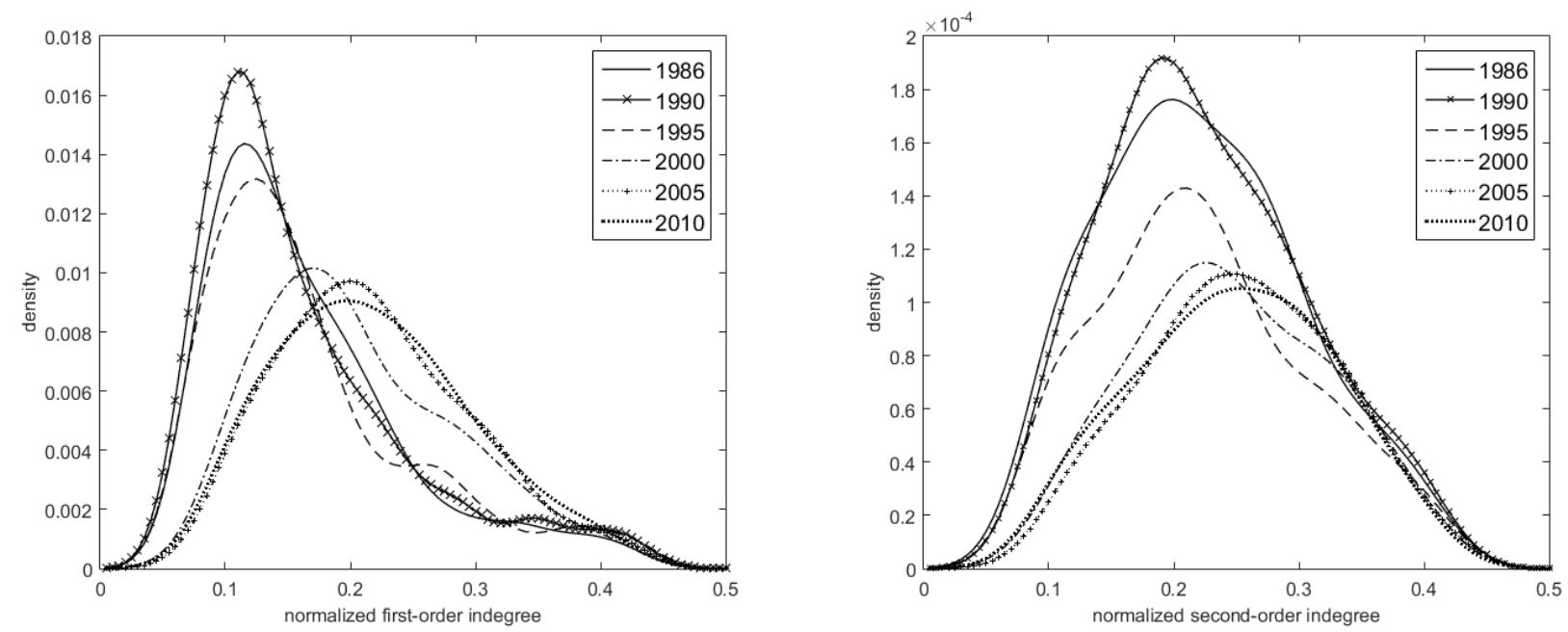

Figure 2. Normalized first-order (left panel) and second-order (right panel) indegree distribution.

Looking at the distribution of indegree (see left panel of Figure 2, in which normalization sets the index

\footnotetext{
${ }^{11}$ Indeed, the network analysis allows us to appreciate that countries featuring the same degree of trade openness (measured for instance as exports plus imports over GDP) may have a very different position within the network.

12 In fact, the same analysis is also carried out on the distributions of the outdegree and total degree (the sum of the in- and outdegree net of bilateral links). The qualitative picture is unchanged. The interested reader will find a sample of results derived from the analysis of the outdegree in Appendix A.
} 
between 0 and 1 for all years to enhance comparability), we can see that alongside a small fraction of highly connected nodes, there is a large group of peripheral countries. However, skewness decreases over time and the distribution becomes more symmetric: over time the body of the distribution shifts rightward, signaling an increase in the number of trade partners to which the average country is connected. This is consistent with results presented by Konar et al. (2011), who find that the distribution of the number of trade connections held by each country follows an exponential distribution, the tail of which becomes thinner over time. Our data confirm these findings show that they extend to 2010 as well. A Lilliefors test performed on the indegree distribution cannot reject the null hypothesis that the distribution is exponential and thus not heavy tailed.

Table 3. Descriptive statistics and indexes of tail-haviness. First- and second-order indegree distributions.

\begin{tabular}{|c|c|c|c|c|c|c|c|c|}
\hline \multirow{3}{*}{ Year } & \multicolumn{4}{|c|}{ First-Order Indegree } & \multicolumn{4}{|c|}{ Second-Order Indegree } \\
\hline & (1) & (2) & (3) & (4) & (5) & (6) & (7) & (8) \\
\hline & Kurtosis & Skewness & $\begin{array}{c}\% \text { Out of } \\
\text { Interval }\end{array}$ & $\begin{array}{c}\text { Obesity } \\
\text { Index }\end{array}$ & Kurtosis & Skewness & $\begin{array}{l}\% \text { Out of } \\
\text { Interval }\end{array}$ & $\begin{array}{c}\text { Obesity } \\
\text { Index }\end{array}$ \\
\hline 1986 & 4.37 & 1.32 & 7.2 & 0.71 & 2.40 & 0.35 & 3.8 & 0.57 \\
\hline 1990 & 4.29 & 1.35 & 7.3 & 0.72 & 2.42 & 0.40 & 4.4 & 0.59 \\
\hline 1995 & 3.95 & 1.24 & 6.3 & 0.71 & 2.39 & 0.37 & 3.4 & 0.58 \\
\hline 2000 & 2.75 & 0.68 & 4.7 & 0.63 & 2.21 & 0.12 & 1.9 & 0.53 \\
\hline 2005 & 2.75 & 0.52 & 3.8 & 0.58 & 2.29 & 0.004 & 2.4 & 0.50 \\
\hline 2010 & 2.55 & 0.44 & 4.2 & 0.57 & 2.21 & -0.04 & 1.0 & 0.49 \\
\hline
\end{tabular}

The same conclusion is further confirmed by the values taken by the Obesity Index (see column 4 of Table 3), which are always lower than the theoretical value under an exponential distribution (0.75) and decrease over time. Similarly, the percentage of observations outside the interval "mean \pm double standard deviation" (column 3 of the table) and the downward sloping shape of the MEF plots (left panel of Figure 3) consistently point in the same direction.

Yet, looking at first-order connectivity may not be enough. In fact, Acemoglu et al. (2012) show that the first-order degree distribution provides only partial information on the network structure. In other words, examining the first-order connectivity only, as the existing literature does, may not be enough to rule out the possibility of cascade effects. Two networks with identical first-order degree distribution may exhibit considerably different levels of vulnerability. This is because country-specific idiosyncratic shocks affect not only the countries immediately connected to it, but also those indirectly connected. As we are interested in discovering possible intrinsic features favoring network instability, we need to explore higher-order connectivity. Following Acemoglu et al. (2012), we compute the second-order degree vector $q_{i}$ of the VW trade network by multiplying the adjacency matrix $A(N x N)$ of the VW network by the degree vector $K$, according to the formula $q_{i} \equiv \sum_{j=1}^{N} a_{i j} k_{j}$, where $k_{j}$ is the degree distribution of node $j$ and $a_{i j}$ is the element of the adjacency matrix $A(N x N)$, which assumes the value of one if there is a link between nodes $i$ and $j$.

Again, this analysis aims to test for the presence of heavy tails and to check the extent to which the tails of the distribution have become heavier over time.

The distribution of second-order degrees (right panel of Figure 2), becomes less skewed over time: the decreasing values of skewness and kurtosis (Table 3, columns 5-6) confirm that the distribution becomes more balanced over time and tails become thinner. In fact, kurtosis is always lower than the reference level for a Gaussian distribution, suggesting the presence of thin tails. This feature is further confirmed by the (decreasing) values of the Obesity Index (column 8 of Table 3) and the downward shape of the MEF plots (right panel of Figure 3). 

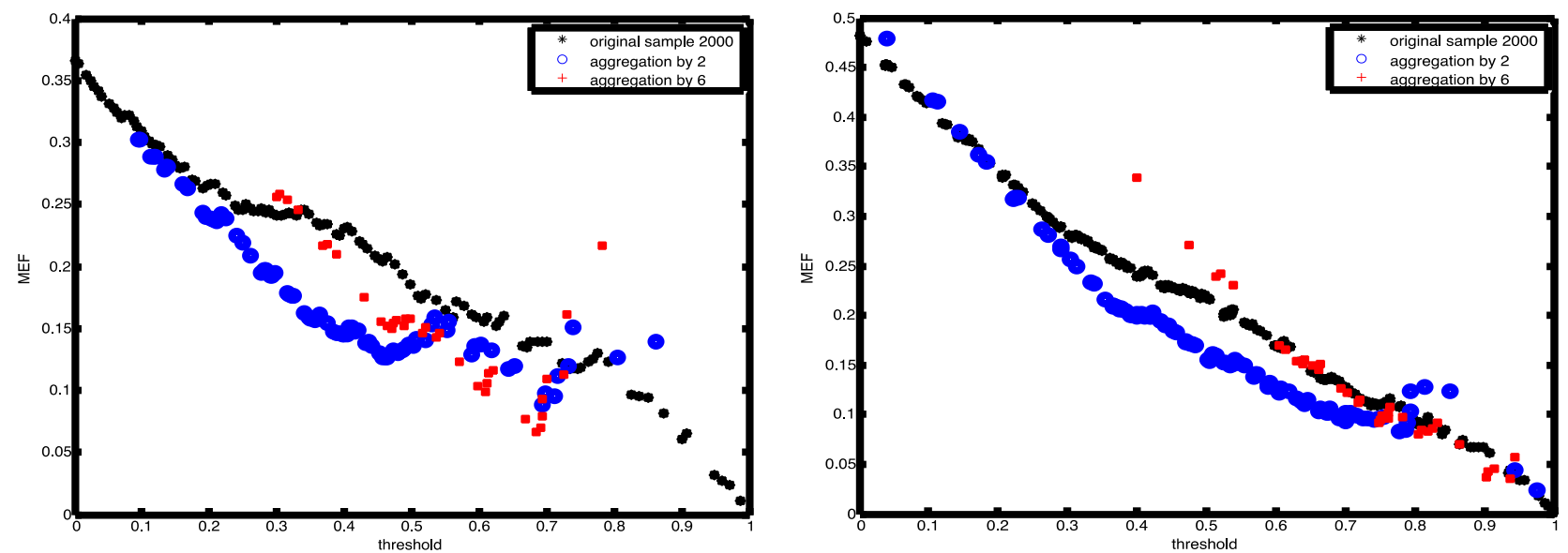

Figure 3. MEF of the original sample and aggregated data set at the year 2000. First-order (left panel) and second-order (right panel) degree distribution.

By interpreting the latter findings together with the qualitative results discussed above, we can conclude that the network structure is becoming more balanced over time. In fact, the data show a reduction in the cross-country heterogeneity in both direct (first-order) and indirect (second-order) connectivity.

This reshaping of the topological structure of the network is driven by the fact that more countries are integrating in the system and playing a more active role in international VW trade, lessening the importance of the dominant players and thus making the system more balanced. This in turn suggests a reduction in systemic vulnerability: a less asymmetric structure of the network implies that the resilience generated by the dissipation of shocks through the network outweighs the fragility effect that comes from the possible propagation of local crises. In other words, in a balanced network disturbances are dissipated at a faster rate and are less likely to generate extreme cascading effects (Battiston et al. 2012; Acemoglu et al. 2012).

Overall, the topological characteristics of the global agricultural trade network (represented by VW flows) suggest that VW trade favors neither country's vulnerability to external crises nor the propagation of shocks through the system.

A further step in the analysis entails considering link weights in the picture, in order to evaluate heterogeneity in the intensity of trade relations, which is normally very large and should not be disregarded (Fagiolo et al. 2010). In the weighted version of the VW trade network, each link is assigned a value $z_{i j}>0$, proportional to the weight of that link. Since we are mainly interested in inflows, the weight $z_{i j}$ for each flow is computed as the ratio of a country's in-flow of VW over the country's outstrength, such that the row $\operatorname{sum} \sum_{j} z_{i j}=1$. Formally, $z_{i j}=w_{i j} / \sum_{j=1}^{n} w_{i j}$. In this way, the weighted VW trade network is fully described by its $(N x N)$ weighted matrix $Z=\left\{z_{i j}\right\}$, where $z_{i j}=0$ for all $i=j$. Figure 4 shows the graphical representation of the weighted first-order and the weighted second-order degree distributions for 1990, 2000, and 2010. Here as well we can see that the distributions become less skewed and more balanced over time (in fact, both skewness and kurtosis decline markedly): this pattern is common to first- and second-order (weighted) indegree, and is particularly relevant since second-order connectivity, which captures indirect links across countries, plays an important role in determining systemic vulnerability (Acemoglu et al. 2012, 2015). 

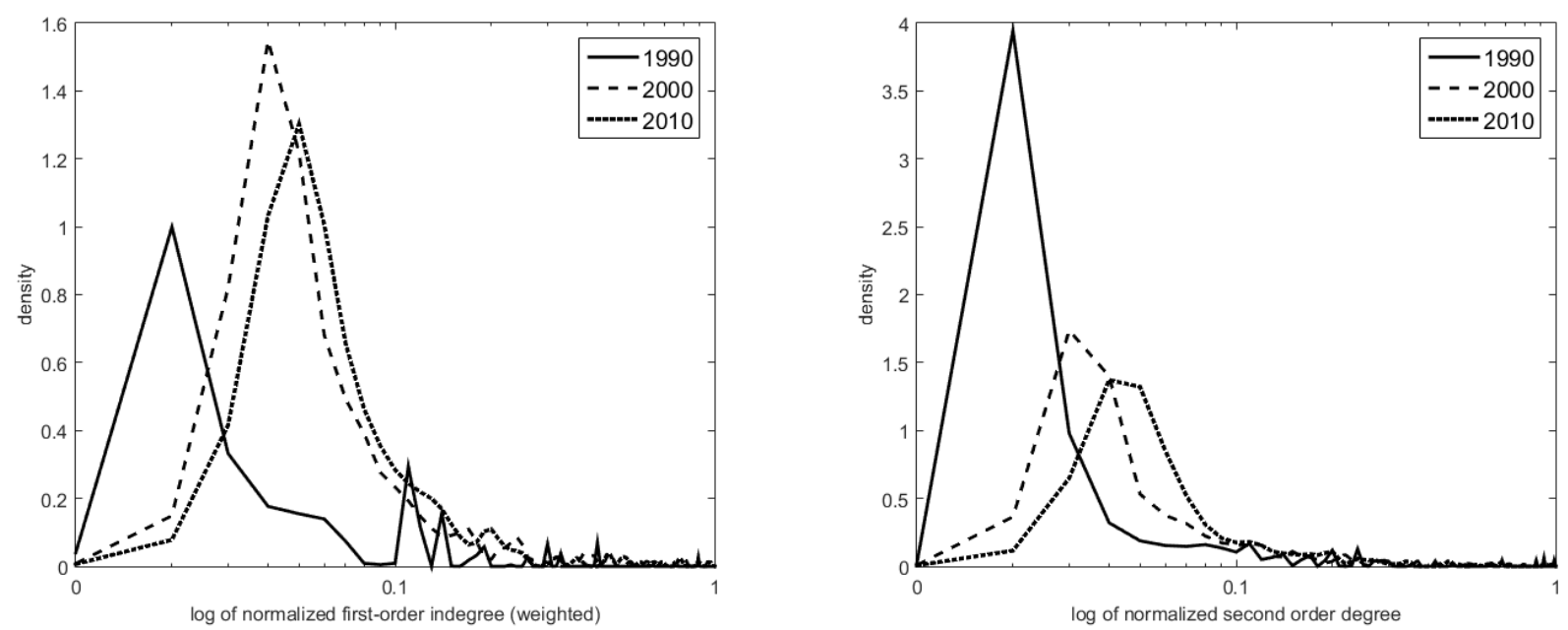

Figure 4. Weighted first- (left panel) and second-order (right panel) indegree distributions for selected years. Horizontal axis in log scale.

The values of the Obesity Index reported in Table 4 are large, well above the expected value implied by an exponential distribution (0.75), but declines over time. The MEF plots displayed in Figure 5 have an inverted-U shape and although the shape does not change dramatically, we do see that upon aggregation the downward sloping part of the MEF appears more evident.

With respect to their unweighted counterparts, both first- and second-order weighted indegree distributions seem to display heavier tails. Different indexes give conflicting results: the share of observations in the upper tail is small but increases over time, whereas the Obesity index displays high values but goes down in more recent years. Also, the inverted U-shape followed by the MEF is not fully consistent with a heavy-tail distribution. Hence, we do not find a clear evidence of heavy tails in the distributions, but at the same time the evidence does not allow us to exclude it completely.

Table 4. Indexes of tail heaviness. Weighted first- and second-order indegree.

\begin{tabular}{c|cc|cc}
\hline Year & $\begin{array}{c}|c| \\
\text { Fobs out of } \\
\text { interval }\end{array}$ & $\begin{array}{c}\mathbf{( 1 )} \\
\text { Obesity } \\
\text { Index }\end{array}$ & $\begin{array}{c}\text { Second-Order Indegree } \\
\text { \% obs out of } \\
\text { interval }\end{array}$ & $\begin{array}{c}\mathbf{( 4 )} \\
\text { Obesity } \\
\text { Index }\end{array}$ \\
\hline $\mathbf{1 9 8 6}$ & 3.4 & 0.93 & 3.8 & 0.91 \\
$\mathbf{1 9 9 0}$ & 3.4 & 0.93 & 4.9 & 0.92 \\
$\mathbf{1 9 9 5}$ & 4.2 & 0.92 & 4.6 & 0.92 \\
$\mathbf{2 0 0 0}$ & 5.2 & 0.89 & 5.2 & 0.89 \\
$\mathbf{2 0 0 5}$ & 5.7 & 0.87 & 4.7 & 0.89 \\
$\mathbf{2 0 1 0}$ & 6.2 & 0.87 & 5.1 & 0.88 \\
\hline
\end{tabular}

The analysis carried out so far has the merit of shedding light on two facts: first, both the unweighted and the weighted analysis of the same network are useful, because different characteristics may be highlighted; second, the first-order interconnections provide only partial information about the structure of the VW network. The need to look at higher-order degree distributions is thus confirmed. 

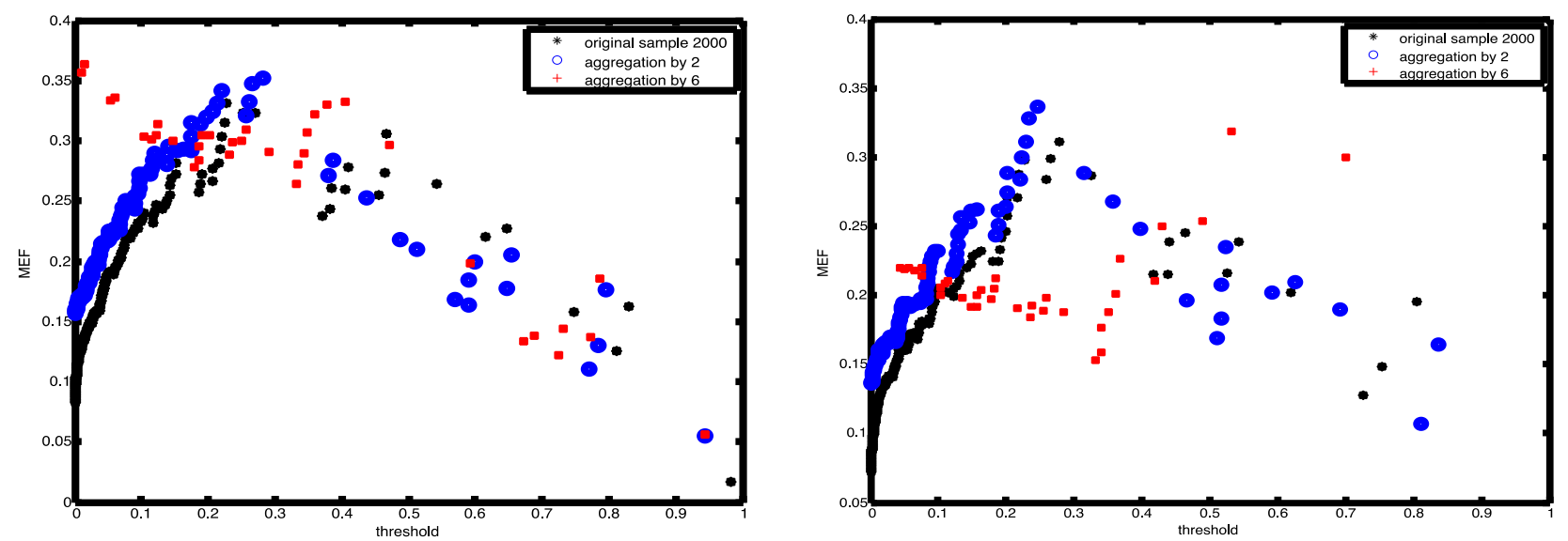

Figure 5. MEF of the original sample and aggregated data set at the year 2000. Weighted first- (left panel) and second-order (right panel) indegree distribution.

\section{Policy implications and concluding remarks}

This work investigates the relationship between countries' participation in international trade in agricultural goods and their vulnerability to external shocks from a network perspective.

Our work contributes to the debate on the potential merits and risks associated with openness to trade in agricultural and food products. On the one hand, trade helps to ensure that even countries with limited water (and other relevant) resources have access to sufficient food and contribute to the global saving of water. On the other hand, there are fears that openness may increase the vulnerability to external shocks and thus make countries worse off. Here we abstract from political considerations about food sovereignty and independence from imports and focus instead on investigating whether the likelihood of large output shocks has increased over time, alongside globalization, and whether the topological features of the network of international trade in agricultural goods makes the world system prone to large systemic crises.

Our analysis reveals a number of interesting and relevant features. First of all, the probability of large supply shocks hitting the system is larger than one would predict under the Normal (Gaussian) distribution, but has not increased over time. Second, the structure of the VW network has become more balanced over time, as more countries integrate further in the world system and increase their import and export activity. As a result, the topological characteristics of the VW network, which play an important role in the transmission of shocks, are not such as to favor the systemic risk associated with shock propagation. The structure of international trade has evolved in a way that makes the benefits from the dissipation of shocks through the network outweigh the potential costs of shock propagation and magnification, at least from a systemic point of view. Yet, the high concentration of trade flows, with a few very strong relations accounting for the bulk of world trade, makes some of the nodes critically important. The analysis of higher-order interconnections reveals important information about the structure of a network: this paper represents an interesting first step in this direction, but further research is needed to identify critical nodes at the global and regional level.

In a nutshell, we find that the increased globalization, witnessed by both the increasing number of trading countries and the increase in total trade flows, is not associated with an increased likelihood of adverse shocks in food production. Furthermore, building on recent advances in network analysis, we find that the world is more interconnected, but not necessarily less stable. While the number of trade connections and the volume of water associated with global food trade has almost doubled, the degree of network asymmetry has decreased. Central players are gradually lessening their importance as dominant-hubs, giving rise to a more balanced topological structure and, therefore, reducing the systemic vulnerability of the VW network. 
From these results we derive two main implications. First, with respect to the relationship between trade openness and food security, we conclude that global trade cannot be regarded as a major source of systemic instability, and policies of national self-sufficiency in food production that progressively reduce a country's participation in agricultural trade may be globally defeating if they end up increasing the heterogeneity in the network. In fact, by highlighting the crucial role of interconnections and second-order linkages across countries, network analysis forcefully shows that international coordination plays a crucial role in making the system more resilient to food crises. Moreover, as discussed by Allouche (2011), in places where water and land are scarce, a target of national selfsufficiency may simply not be viable or, by increasing pressure on natural resources, become unsustainable in the long-run.

Second, from a policy perspective our results suggest that the process of globalization in food trade makes countries strongly interdependent. Hence, none of them can imagine to be completely insulated from external shocks. As a result, international coordination should be enhanced. In fact, isolated moves by individual countries seeking to limit their exposure may have unintended global consequences if they alter the topological structure of the network (for instance by increasing its heterogeneity). On the contrary, concerted actions are more likely to make the global system more resilient to food crises, as already emphasized in a recent contribution by Rutten et al. (2013). For instance, an effort to reduce the remaining trade barriers to trade in agricultural goods would offer new trade opportunities: as long as this also reduces heterogeneity in the network -for instance by enhancing the integration of peripheral countries- it would have a beneficial effect on stability.

We claim network analysis can offer a fruitful avenue of research in the area of food security. Looking at commodity-specific networks more directly related with food security in some part of the world (e.g. grains, rice or other staple food) may highlight important features that are not evident in the aggregated analysis performed here. Furthermore, in this paper we have deliberately focused on the global stability of the network, abstracting from analyzing the position of each and every country. Investigating the presence of regional or country-specific fragilities represents another interesting avenue for further research.

\section{References}

Acemoglu, D., Carvalho, V. M., Ozdaglar, A., and Tahbaz-Salehi, A. (2012). The network origins of aggregate fluctuations. Econometrica, 80, 1977-2016.

Acemoglu, D., Ozdaglar, A., and Tahbaz-Salehi, A. (2013). The network origins of large economic downturns. Working Paper 19230, National Bureau of Economic Research.

Acemoglu, D., Ozdaglar, A., and Tahbaz-Salehi, A. (2015). Networks, Shocks, and Systemic Risk. Working Paper 20931, National Bureau of Economic Research.

Allan, J. A. (1993). Fortunately there are substitutes for water otherwise our hydro-political futures would be impossible, priorities for water resources allocation and management (pp. 13-26). London: ODA.

Allen, F., and Babus, A. (2009). Networks in finance. In P. Kleindorfer and J. Wind (Eds.), The Network Challenge (pp. 367-382). Wharton School Publishing, New Jersey.

Allouche, J. (2011). The sustainability and resilience of global water and food systems: Political analysis of the interplay between security, resource scarcity, political systems and global trade. Food Policy, 36(S1), S3-S8.

Antonelli, M., and Sartori M. (2015). Unfolding the potential of the virtual water concept. What is still under debate? Environmental Science and Policy, 50, 240-251.

Battiston, S., Puliga, M., Kaushik, R., Tasca, P., and Caldarelli, G. (2012). Debtrank: Too central to fail? Financial networks, the FED and systemic risk. Scientific Reports, 2, 1-6. 
Boguna, M., and Pastor-Satorras, R. (2003). Class of correlated random networks with hidden variables. Physical Review E, 68, 036112.

Bonacich, P. (1972). Factoring and weighting approaches to status scores and clique identification. Journal of Mathematical Sociology, 2, 176-185.

Bougheas, S., and Kirman, A. (2014). Complex financial networks and systemic risk: A review. CESifo Working Paper 4756.

Burnecki K., and Weron, R. (2008), Visualization tools for insurance risk problem, published in Handbook of data visualization, edited by Chen C., Haerdle W., and Unwin A. Springer, Berlin.

Burnett, K., and Murphy, S. (2014). What place for international trade in food sovereignty? Journal of Peasant Studies, 41(6), 1065-1084.

Caccioli, F., Catanach, T. A., and Farmer, J. D. (2012). Heterogeneity, correlations and financial contagion. Advances in Complex Systems, 15(2), 1250058.

Carlson, J., and Doyle, J. (2002). Complexity and robustness. Proceedings of the National Academy of Sciences, 99, 2538-2545.

Carr, J., D'Odorico, P., Laio, F., and Ridolfi, L. (2012). On the temporal variability of the virtual water network. Geophysical Research Letters, 39(6), 7.

Carr, J., D’Odorico, P., Laio, F., and Ridolfi, L. (2013). Recent history and geography of virtual water trade. PLOS ONE Public Library of Science, 8(2), e55825.

Clauset, A., Shalizi, C., and Newman, M. (2009). Power law distribution in empirical data. SLAM Review, 51(4), 661-703.

Cooke, R. M., Nieboer, D. and Misiewicz, J. (2014). Fat-tailed distributions: Data diagnostics, and dependence. Wiley-ISTE.

Dalin, C., Konar, M., Hanasaki, N., Rinaldo, A., and Rodriguez-Iturbe, I. (2012). Evolution of the global virtual water trade network. Proceedings of the National Academy of Sciences, 109(16), 5989-5994.

Dilley, M., and Boundreau, T.E. (2001). Coming to terms with vulnerability: a critique of the food security definition. Food Policy, 26, 229-247.

D’Odorico, P., Carr, J., Laio, F., and Ridolfi, L. (2012). Spatial organization and drivers of the virtual water trade: A community-structure analysis. Environmental Research Letters, 7, 034007.

Doyle, J., Alderson, D., Li, L., Low, S., Roughan, M., Shalunov, S., Tanaka, R., and Willinger, W. (2005). The "robust yet fragile" nature of the Internet. Proceedings of the National Academy of Sciences, 102, 14497-14502.

Fagiolo, G., Reyes, J., and Schiavo, S. (2010). The evolution of the world trade web: A weighted network approach. Journal of Evolutionary Economics, 20(4), 479-514.

Ghosh, S., and Resnick, S. (2010). A discussion on mean excess plots, Stochastic Processes and their Applications, $120(8), 1492-1517$.

Haldane, A., and May, R. (2011). Systemic risk in banking ecosystems. Nature, 469, 351-355.

Headey, D. (2011). Rethinking the global food crisis: The role of trade shocks, Food Policy, 36, 136-146.

Hoekstra, A.Y., and Hung, P.Q. (2002). Virtual water trade: A quantification of virtual water flows between nations in relation to international crop trade. Value of Water Research Report Series, 11, IHE, Delft.

Hoekstra, A.Y., and Chapagain, A. (2008). Globalization of water: Sharing the planet's freshwater resources. Oxford: Blackwell Publishing.

Huang H., von Lampe, M., and van Tongeren, F. (2011). Climate change and trade in agriculture, Food Policy, 36, S9-S13.

Hubbard, L.J., and Hubbard, C. (2013). Food security in the United Kingdom: external supply risks. Food Policy, 43, 142-147.

Iori, G., Jafarey, S., and Padilla, F. G. (2006). Systemic risk on the interbank market. Journal of Economic 
Behavior and Organization, 61, 525-542.

Konar, M., Dalin, C., Suweis, S., Hanasaki, N., Rinaldo, A., and Rodriguez-Iturbe, I. (2011). Water for food: The global virtual water trade network. Water Resources Research, 47, W05520.

Matthews, A. (2014), Trade rules, food security and the multilateral trade negotiations, European Review of Agricultural Economics, 41(3), 511-535.

Mekonnen, M. M., and Hoekstra, A. Y. (2011). The green, blue and grey water footprint of crops and derived crop products. Hydrology and Earth System Sciences, 15, 1577-1600.

Montalbano, P. (2011). Trade Openness and Developing Countries' Vulnerability: Concepts, Misconceptions, and Directions for Research, World Development, 39(9), 1489-1502.

Newman, M. (2003), The structure and function of complex networks, SLAM Review, vol.45, pp.167256.

Oki, T., and Kanae, S. (2004). Virtual water trade and world water resources. Water Science and Technology, 49(7), 203-209.

Paarlberg, R. (2000). The weak link between world food markets and world food security. Food Policy, 25(3), 317-335.

Roson R., and Sartori, M. (2015). Virtual Water Trade in the Mediterranean: Today and Tomorrow in Antonelli M. and Greco F. (eds.) The Water We Eat-combining virtual water and water footprints, Springer.

Rutten, M., Shutes, L., and Meijerink, G. (2013). Sit down at the ball game: how trade barriers make the world less food secure. Food Policy, 38, 1-10.

Shutters, S. T., and Muneepeerakul, R. (2012). Agricultural trade networks and patterns of economic development. PLOS ONE, 7, e39756.

Suweis, S., Konar, M., Dalin, C., Hanasaki, N., Rinaldo, A., and Rodriguez-Iturbe, I. (2011). Structure and controls of the global virtual water trade network. Geophysical Research Letters, 38, L10403. doi:10.1029/2011GL046837

Tamea, S., Carr, J. A., Laio, F., and Ridolfi, L. (2014). Drivers of the virtual water trade. Water Resources Research, 50, 17-28.

Tamea, S., Allamano, P., Carr, J. A., Claps, P., Laio, F., and Ridolfi, L. (2013). Local and global perspectives on the virtual water trade. Hydrology and Earth System Sciences, 17, 1205-1215.

Tanaka, T., and Hosoe, N. (2011), "Does agricultural trade liberalization increase risks of supply-side uncertainty?: Effects of productivity shocks and export restrictions on welfare and food supply in Japan", Food Policy, 36(3), 368-377. 


\section{Appendix A}

We present a sample of results derived from the analysis of the outdegree probability distribution functions, for the same selected years. A comparison with the indegree analysis carried out previously shows that the qualitative picture does not change.
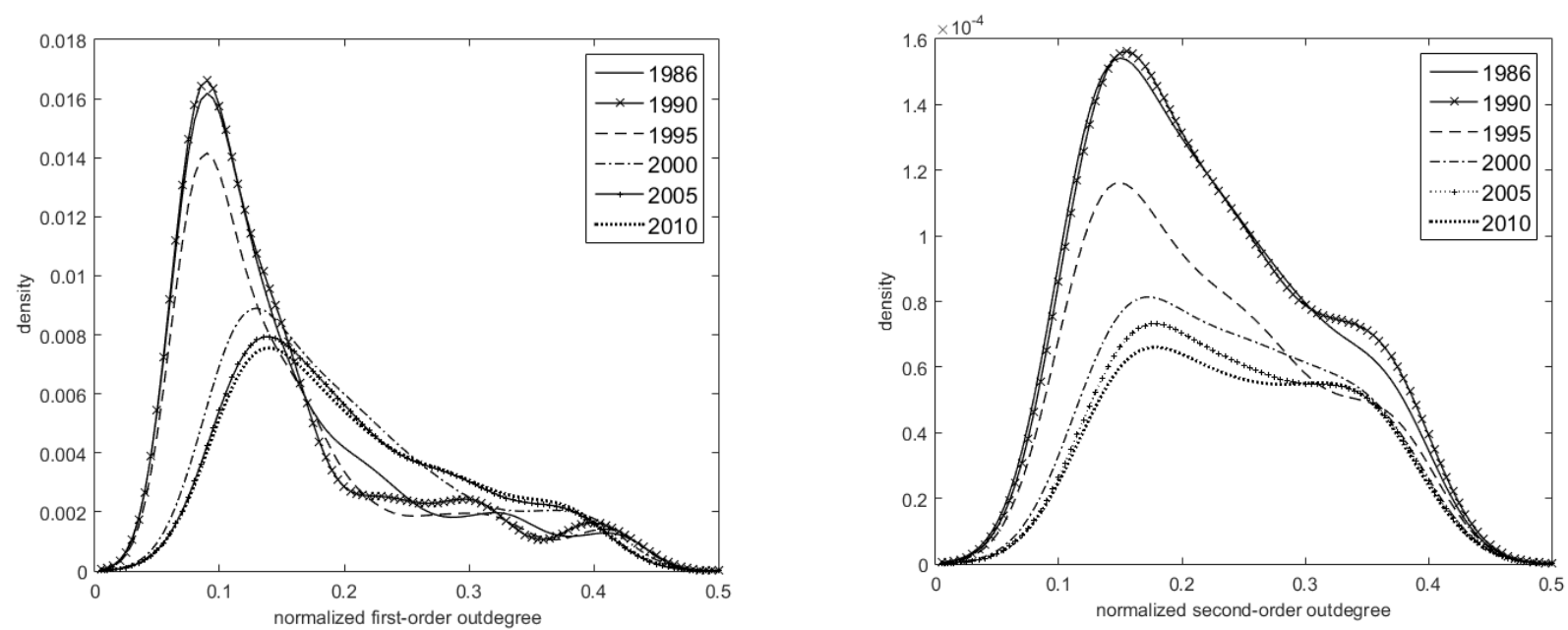

Figure A1. Normalized first-order (left panel) and second-order (right panel) outdegree distributions.

Table A1. Descriptive statistics and indexes of tail heaviness. First- and second-order outdegree distributions.

\begin{tabular}{c|cccc|cccc}
\hline \multirow{2}{*}{ Year } & \multicolumn{3}{|c|}{ First-Order Outdegree } & \multicolumn{4}{c}{ Second-Order Indegree } \\
\cline { 2 - 10 } & Kurtosis & Skewness & $\begin{array}{c}\text { \% Out of } \\
\text { Interval }\end{array}$ & ObIn & Kurtosis & Skewness & $\begin{array}{c}\text { \% Out of } \\
\text { Interval }\end{array}$ & ObInd. \\
\hline $\mathbf{1 9 8 6}$ & 4.11 & 1.40 & 6.7 & 0.78 & 2.09 & 0.52 & 2.4 & 0.6463 \\
$\mathbf{1 9 9 0}$ & 4.06 & 1.41 & 6.3 & 0.78 & 2.03 & 0.50 & 1.5 & 0.6361 \\
$\mathbf{1 9 9 5}$ & 3.97 & 1.37 & 5.9 & 0.78 & 2.07 & 0.52 & 2.1 & 0.6460 \\
$\mathbf{2 0 0 0}$ & 2.75 & 0.88 & 7.0 & 0.70 & 1.80 & 0.26 & 0 & 0.5737 \\
$\mathbf{2 0 0 5}$ & 2.39 & 0.73 & 5.2 & 0.69 & 1.71 & 0.23 & 0 & 0.5730 \\
$\mathbf{2 0 1 0}$ & 2.27 & 0.68 & 4.3 & 0.68 & 1.63 & 0.15 & 0 & 0.5471 \\
\hline
\end{tabular}
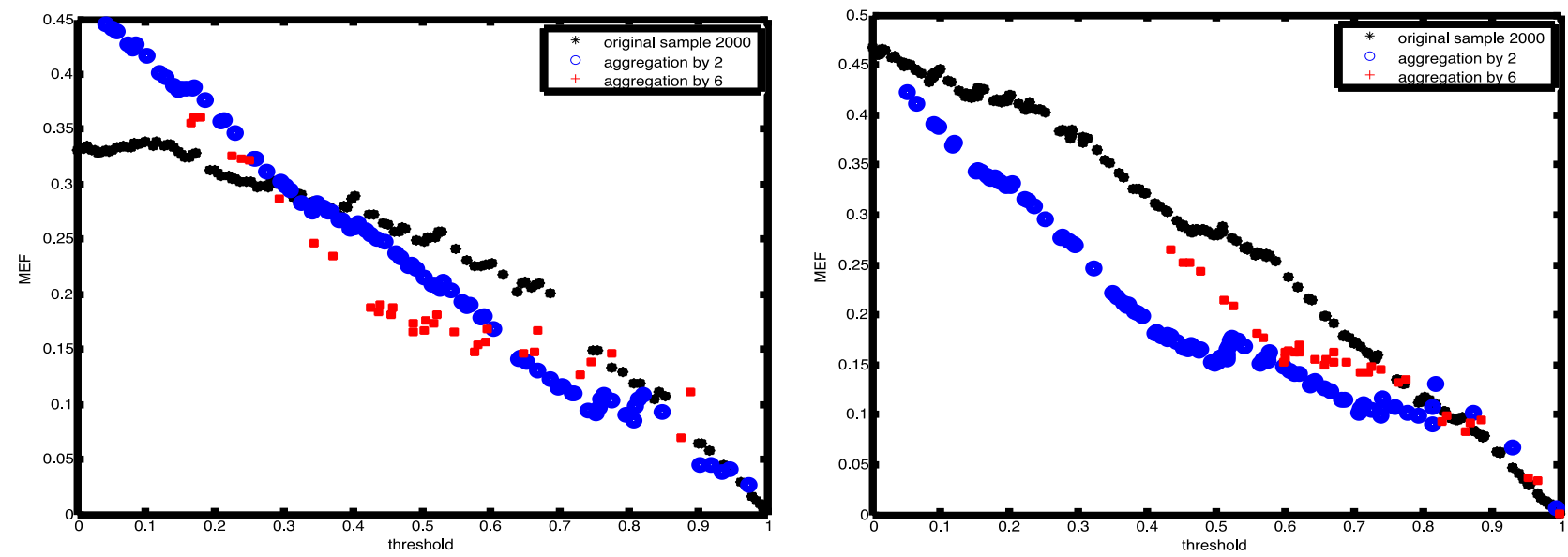

Figure A2. MEF of the original sample and aggregated data set at the year 2000. First-order (left panel) and second-order (right panel) degree distribution of the unweighted VW network. 



Figure A3. Weighted first-order (left panel) and second-order (right panel) outdegree distributions for selected years. Horizontal axis in $\log$ scale.

Table A2. Indexes of tail heaviness. Weighted first- and second-order outdegree.

\begin{tabular}{c|cc|cc}
\hline \multirow{2}{*}{ Year } & \multicolumn{2}{|c|}{ First-Order Outdegree } & \multicolumn{2}{|c}{ Second-Order Outdegree } \\
\cline { 2 - 5 } & $\begin{array}{c}\text { \% Out of } \\
\text { Interval }\end{array}$ & ObIn & $\begin{array}{c}\text { \% Out of } \\
\text { Interval }\end{array}$ & ObInd. \\
\hline $\mathbf{1 9 8 6}$ & 2.5 & 0.9284 & 3.9 & 0.9220 \\
$\mathbf{1 9 9 0}$ & 2.9 & 0.9425 & 4.4 & 0.9275 \\
$\mathbf{1 9 9 5}$ & 3.8 & 0.9348 & 5.1 & 0.9193 \\
$\mathbf{2 0 0 0}$ & 3.8 & 0.9062 & 5.2 & 0.9040 \\
$\mathbf{2 0 0 5}$ & 4.3 & 0.9054 & 4.8 & 0.9074 \\
$\mathbf{2 0 1 0}$ & 4.3 & 0.9032 & 4.7 & 0.9112 \\
\hline
\end{tabular}
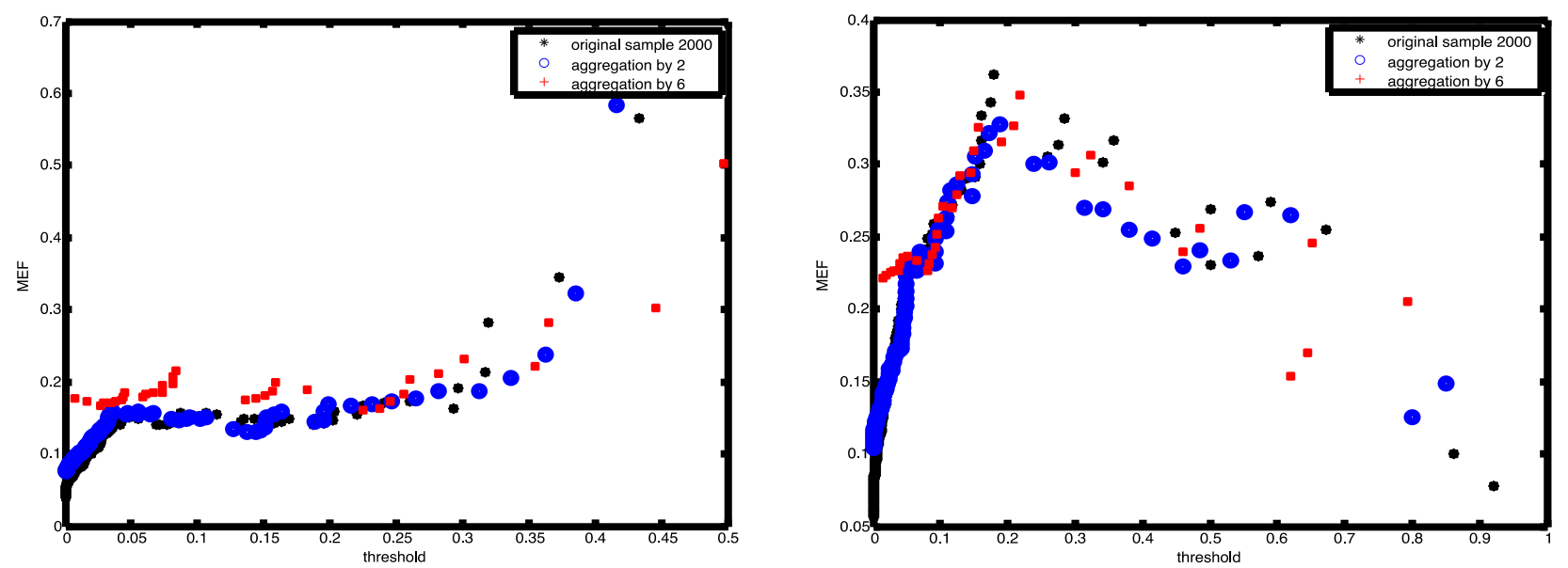

Figure A4. MEF of the original sample and aggregated data set at the year 2000. Weighted first-order (left panel) and second-order (right panel) outdegree distribution. 


\section{Appendix B}

Table B1. List of countries.

\begin{tabular}{|c|c|c|c|c|c|}
\hline id & Countries & id & Countries & id & Countries \\
\hline 1 & Afghanistan & 46 & China, Hong Kong SAR & 91 & Ghana \\
\hline 2 & Albania & 47 & China, Macao SAR & 92 & Gibraltar \\
\hline 3 & Algeria & 48 & China, Taiwan Province of & 93 & Greece \\
\hline 4 & American Samoa & 49 & China, mainland & 94 & Greenland \\
\hline 5 & Andorra & 50 & Christmas Island & 95 & Grenada \\
\hline 6 & Angola & 51 & Cocos (Keeling) Islands & 96 & Guadeloupe \\
\hline 7 & Anguilla & 52 & Colombia & 97 & Guam \\
\hline 8 & Antarctica & 53 & Comoros & 98 & Guatemala \\
\hline 9 & Antigua and Barbuda & 54 & Congo & 99 & Guinea \\
\hline 10 & Argentina & 55 & Cook Islands & 100 & Guinea-Bissau \\
\hline 11 & Armenia & 56 & Costa Rica & 101 & Guyana \\
\hline 12 & Aruba & 57 & Croatia & 102 & Haiti \\
\hline 13 & Australia & 58 & Cuba & 103 & Heard and McDonald Is. \\
\hline 14 & Austria & 59 & Cyprus & 104 & Holy See \\
\hline 15 & Azerbaijan & 60 & Czech Republic & 105 & Honduras \\
\hline 16 & Bahamas & 61 & Czechoslovakia & 106 & Hungary \\
\hline 17 & Bahrain & 62 & Côte d'Ivoire & 107 & Iceland \\
\hline 18 & Bangladesh & 63 & $\begin{array}{l}\text { Dem. People's Rep. of } \\
\text { K nres }\end{array}$ & 108 & India \\
\hline 19 & Barbados & 64 & Dem. Rep. of the Congo & 109 & Indonesia \\
\hline 20 & Belarus & 65 & Denmark & 110 & Iran (Islamic Republic of) \\
\hline 21 & Belgium & 66 & Djibouti & 111 & Iraq \\
\hline 22 & Belize & 67 & Dominica & 112 & Ireland \\
\hline 23 & Benin & 68 & Dominican Republic & 113 & Israel \\
\hline 24 & Bermuda & 69 & EU(12)ex.int & 114 & Italy \\
\hline 25 & Bhutan & 70 & Ecuador & 115 & Jamaica \\
\hline 26 & Bolivia & 71 & Egypt & 116 & Japan \\
\hline 27 & Bosnia and Herzegovina & 72 & El Salvador & 117 & Johnston Island \\
\hline 28 & Botswana & 73 & Equatorial Guinea & 118 & Jordan \\
\hline 29 & Bouvet Island & 74 & Eritrea & 119 & Kazakhstan \\
\hline 30 & Brazil & 75 & Estonia & 120 & Kenya \\
\hline 31 & British Ind. Ocean Terr. & 76 & Ethiopia & 121 & Kiribati \\
\hline 32 & British Virgin Islands & 77 & Falkland Islands (Malvinas) & 122 & Kuwait \\
\hline 33 & Brunei Darussalam & 78 & Faroe Islands & 123 & Kyrgyzstan \\
\hline 34 & Bulgaria & 79 & Fiji & 124 & Lao People's Dem. Rep. \\
\hline 35 & Burkina Faso & 80 & Finland & 125 & Latvia \\
\hline 36 & Burundi & 81 & France & 126 & Lebanon \\
\hline 37 & Cambodia & 82 & French Guiana & 127 & Lesotho \\
\hline 38 & Cameroon & 83 & French Polynesia & 128 & Liberia \\
\hline 39 & Canada & 84 & French South. Ant. Terr. & 129 & Libyan Arab Jamahiriya \\
\hline 40 & Canton and Enderbury Is. & 85 & Gabon & 130 & Liechtenstein \\
\hline 41 & Cape Verde & 86 & Gambia & 131 & Lithuania \\
\hline 42 & Cayman Islands & 87 & Gaza Strip (Palestine) & 132 & Luxembourg \\
\hline 43 & Central African Republic & 88 & Georgia & 133 & Madagascar \\
\hline 44 & Chad & 89 & Germany & 134 & Malawi \\
\hline 45 & Chile & 90 & Germany Nl & 135 & Malaysia \\
\hline
\end{tabular}


Table B1. (continue...).

\begin{tabular}{|c|c|c|c|c|c|}
\hline id & Countries & id & Countries & id & Countries \\
\hline 136 & Maldives & 176 & Peru & 216 & Sweden \\
\hline 137 & Mali & 177 & Philippines & 217 & Switzerland \\
\hline 138 & Malta & 178 & Pitcairn Islands & 218 & Syrian Arab Republic \\
\hline 139 & Marshall Islands & 179 & Poland & 219 & Tajikistan \\
\hline 140 & Martinique & 180 & Portugal & 220 & Thailand \\
\hline 141 & Mauritania & 181 & Puerto Rico & 221 & Macedonia (FYR) \\
\hline 142 & Mauritius & 182 & Qatar & 222 & Timor-Leste \\
\hline 143 & Mayotte & 183 & Republic of Korea & 223 & Togo \\
\hline 144 & Mexico & 184 & Republic of Moldova & 224 & Tokelau \\
\hline 145 & Micronesia & 185 & Romania & 225 & Tonga \\
\hline 146 & Midway Island & 186 & Russian Federation & 226 & Trinidad and Tobago \\
\hline 147 & Monaco & 187 & Rwanda & 227 & Tunisia \\
\hline 148 & Mongolia & 188 & Réunion & 228 & Turkey \\
\hline 149 & Montenegro & 189 & Saint Helena & 229 & Turkmenistan \\
\hline 150 & Montserrat & 190 & Saint Kitts and Nevis & 230 & Turks and Caicos Islands \\
\hline 151 & Morocco & 191 & Saint Lucia & 231 & Tuvalu \\
\hline 152 & Mozambique & 192 & Saint Pierre and Miquelon & 232 & US Minor Is. \\
\hline 153 & Myanmar & 193 & Saint Vincent and the Gren. & 233 & USSR \\
\hline 154 & Namibia & 194 & Samoa & 234 & Uganda \\
\hline 155 & Nauru & 195 & San Marino & 235 & Ukraine \\
\hline 156 & Nepal & 196 & Sao Tome and Principe & 236 & United Arab Emirates \\
\hline 157 & Netherlands & 197 & Saudi Arabia & 237 & United Kingdom \\
\hline 158 & Netherlands Antilles & 198 & Senegal & 238 & United Rep. of Tanzania \\
\hline 159 & New Caledonia & 199 & Serbia & 239 & United States Virgin Islands \\
\hline 160 & New Zealand & 200 & Serbia and Montenegro & 240 & United States of America \\
\hline 161 & Nicaragua & 201 & Seychelles & 241 & Uruguay \\
\hline 162 & Niger & 202 & Sierra Leone & 242 & Uzbekistan \\
\hline 163 & Nigeria & 203 & Singapore & 243 & Vanuatu \\
\hline 164 & Niue & 204 & Slovakia & 244 & Venezuela \\
\hline 165 & Norfolk Island & 205 & Slovenia & 245 & Viet Nam \\
\hline 166 & Northern Mariana Islands & 206 & Solomon Islands & 246 & Wake Island \\
\hline 167 & Norway & 207 & Somalia & 247 & Wallis and Futuna Islands \\
\hline 168 & Occ. Palestinian Terr. & 208 & South Africa & 248 & West Bank \\
\hline 169 & Oman & 209 & South Georgia Sandwich Is. & 249 & Western Sahara \\
\hline 170 & Pacific Islands Trust Terr. & 210 & Spain & 250 & Yemen \\
\hline 171 & Pakistan & 211 & Sri Lanka & 251 & Yugoslav SFR \\
\hline 172 & Palau & 212 & Sudan & 252 & Zambia \\
\hline 173 & Panama & 213 & Suriname & 253 & Zimbabwe \\
\hline 174 & Papua New Guinea & 214 & Svalbard and Jan Mayen Is. & & \\
\hline 175 & Paraguay & 215 & Swaziland & & \\
\hline
\end{tabular}


Table B2. List of the 309 items considered in the analysis, with corresponding FAOSTAT identification number.

\begin{tabular}{|c|c|c|c|c|c|}
\hline id & FAO Products & id & FAO Products & id & FAO Product \\
\hline 15 & Wheat & 150 & Flour of Roots and Tubers & 243 & Groundnuts Shelled \\
\hline 16 & Flour of Wheat & 156 & Sugar cane & 244 & Groundnut oil \\
\hline 18 & Macaroni & 157 & Sugar beet & 249 & Coconuts \\
\hline 20 & Bread & 160 & Maple Sugar and Syrups & 251 & Copra \\
\hline 27 & Rice, paddy & 161 & Sugar crops, nes & 252 & Coconut (copra) oil \\
\hline 28 & Rice Husked & 162 & Sugar Raw Centrifugal & 256 & Palm kernels \\
\hline 31 & Rice Milled & 164 & Sugar Refined & 257 & Palm oil \\
\hline 32 & Rice Broken & 165 & Molasses & 258 & Palm kernel oil \\
\hline 38 & Rice Flour & 166 & Other Fructose and Syrup & 259 & Cake of Palm Kernel \\
\hline 44 & Barley & 167 & Sugar, nes & 260 & Olives \\
\hline 46 & Barley Pearled & 171 & Sugar flavoured & 261 & Olive oil, virgin \\
\hline 48 & Barley Flour and Grits & 172 & Glucose and Dextrose & 262 & Olives Preserved \\
\hline 49 & Malt & 176 & Beans, dry & 263 & Karite Nuts (Sheanuts) \\
\hline 51 & Beer of Barley & 181 & Broad and horse beans, dry & 264 & Butter of Karite Nuts \\
\hline 56 & Maize & 187 & Peas, dry & 265 & Castor oil seed \\
\hline 58 & Flour of Maize & 191 & Chick peas & 266 & Oil of Castor Beans \\
\hline 60 & Maize oil & 195 & Cow peas, dry & 267 & Sunflower seed \\
\hline 71 & Rye & 197 & Pigeon peas & 268 & Sunflower oil \\
\hline 72 & Flour of Rye & 201 & Lentils & 269 & Sunflower Cake \\
\hline 75 & Oats & 203 & Bambara beans & 270 & Rapeseed \\
\hline 76 & Oats Rolled & 205 & Vetches & 271 & Rapeseed oil \\
\hline 79 & Millet & 210 & Lupins & 272 & Cake of Rapeseed \\
\hline 83 & Sorghum & 211 & Pulses, nes & 273 & Olive Residues \\
\hline 89 & Buckwheat & 212 & Flour of Pulses & 278 & Oil of Jojoba \\
\hline 92 & Quinoa & 216 & Brazil nuts, with shell & 280 & Safflower seed \\
\hline 94 & Fonio & 217 & Cashew nuts, with shell & 289 & Sesame seed \\
\hline 97 & Triticale & 220 & Chestnuts & 290 & Sesame oil \\
\hline 101 & Canary seed & 221 & Almonds, with shell & 292 & Mustard seed \\
\hline 103 & Mixed grain & 222 & Walnuts, with shell & 296 & Poppy seed \\
\hline 108 & Cereals, nes & 223 & Pistachios & 299 & Melonseed \\
\hline 116 & Potatoes & 224 & Kolanuts & 329 & Cottonseed \\
\hline 117 & Potatoes Flour & 225 & Hazelnuts, with shell & 331 & Cottonseed oil \\
\hline 118 & Frozen Potatoes & 226 & Arecanuts & 332 & Cake of Cottonseed \\
\hline 120 & Potato Offals & 231 & Almonds Shelled & 333 & Linseed \\
\hline 121 & Tapioca of Potatoes & 232 & Walnuts Shelled & 334 & Linseed oil \\
\hline 122 & Sweet potatoes & 233 & Hazelnuts Shelled & 335 & Cake of Linseed \\
\hline 125 & Cassava & 234 & Nuts, nes & 336 & Hempseed \\
\hline 126 & Flour of Cassava & 235 & Prepared Nuts & 339 & Oilseeds, Nes \\
\hline 127 & Tapioca of Cassava & 236 & Soybeans & 340 & Oil of vegetable origin, nes \\
\hline 128 & Cassava Dried & 237 & Soybean oil & 358 & Cabbages \\
\hline 129 & Cassava Starch & 238 & Cake of Soybeans & 366 & Artichokes \\
\hline 135 & Yautia (cocoyam) & 239 & Soya Sauce & 367 & Asparagus \\
\hline 136 & Taro (cocoyam) & 240 & Soya Paste & 372 & Lettuce and chicory \\
\hline 137 & Yams & 241 & Soya curd & 373 & Spinach \\
\hline 149 & Roots and Tubers, nes & 242 & Groundnuts, with shell & 388 & Tomatoes \\
\hline
\end{tabular}


Table B2. (continue...).

\begin{tabular}{|c|c|c|c|c|c|}
\hline id & FAO Products & id & FAO Products & id & FAO Products \\
\hline 389 & Tomatojuice Conc. & 536 & Plums and sloes & 698 & Cloves \\
\hline 390 & Juice of Tomatoes & 537 & Plums Dried (Prunes) & 702 & Nutmeg, mace and card. \\
\hline 391 & Paste of Tomatoes & 541 & Stone fruit, nes & 711 & Anise, badian, fennel \\
\hline 392 & Tomato Peeled & 544 & Strawberries & 720 & Ginger \\
\hline 393 & Cauliflowers and broccoli & 547 & Raspberries & 723 & Spices, nes \\
\hline 394 & Pumpkins, squash & 549 & Gooseberries & 748 & Peppermint \\
\hline 397 & Cucumbers and gherkins & 550 & Currants & 767 & Cotton lint \\
\hline 399 & Eggplant-baseds & 552 & Blueberries & 768 & Cotton Carded,Combed \\
\hline 401 & Chillies and peppers & 554 & Cranberries & 769 & Cotton Waste \\
\hline 402 & Onions (inc. shallots) & 558 & Berries Nes & 770 & Cotton Linter \\
\hline 403 & Onions, dry & 560 & Grapes & 773 & Flax fibre and tow \\
\hline 406 & Garlic & 561 & Raisins & 774 & Flax Tow Waste \\
\hline 414 & Beans, green & 562 & Grape Juice & 777 & Hemp Tow Waste \\
\hline 417 & Peas, green & 563 & Must of Grapes & 780 & Jute \\
\hline 423 & String beans & 564 & Wine & 782 & Other Bastfibres \\
\hline 426 & Carrots and turnips & 565 & Vermouths and Similar & 788 & Ramie \\
\hline 430 & Okra & 566 & Marc of Grapes & 789 & Sisal \\
\hline 446 & Maize, green & 567 & Watermelons & 800 & Agave Fibres Nes \\
\hline 447 & Sweet Corn Frozen & 568 & Other melons & 809 & Manila Fibre (Abaca) \\
\hline 460 & Veg.Prod.Fresh Or Dried & 569 & Figs & 821 & Fibre Crops Nes \\
\hline 461 & Carobs & 571 & Mangoes, mangosteens & 826 & Tobacco, unmanufactured \\
\hline 463 & Vegetables fresh nes & 572 & Avocados & 836 & Natural rubber \\
\hline 466 & Juice of Vegetables Nes & 574 & Pineapples & 866 & Cattle \\
\hline 469 & Vegetables Dehydrated & 576 & Juice of Pineapples & 867 & Cattle meat \\
\hline 471 & Vegetables in Vinegar & 577 & Dates & 868 & Offals of cattle, edible \\
\hline 472 & Vegetables Preserved Nes & 591 & Cashew apple & 870 & Meat-Cattle, boneless \\
\hline 473 & Vegetable Frozen & 592 & Kiwi fruit & 872 & Meat of Beef,Drd \\
\hline 486 & Bananas & 600 & Papayas & 874 & Sausage Beef and Veal \\
\hline 489 & Plantains & 603 & Fruit, tropical fresh nes & 882 & Cow milk, whole, fresh \\
\hline 490 & Oranges & 604 & Fruit Tropical Dried Nes & 886 & Butter Cow Milk \\
\hline 491 & Orange juice & 619 & Fruit Fresh Nes & 888 & Milk Skm of Cows \\
\hline 495 & Tangerines, mandarins & 622 & Fruit Juice Nes & 889 & Milk Whole Cond \\
\hline 497 & Lemons and limes & 656 & Coffee, green & 890 & Whey Condensed \\
\hline 507 & Grapefruit (inc. pomelos) & 657 & Coffee Roasted & 891 & Yoghurt \\
\hline 509 & Juice of Grapefruit & 661 & Cocoa beans & 893 & Butterm.,Curdl,Acid.Milk \\
\hline 512 & Citrus fruit, nes & 662 & Cocoa Paste & 897 & Milk Whole Dried \\
\hline 513 & Citrus juice, & 663 & Cocoahusks;Shell & 898 & Milk Skimmed Dry \\
\hline 515 & Apples & 664 & Cocoa Butter & 901 & Cheese of Whole Cow Milk \\
\hline 517 & Cider Etc & 665 & Cocoapowder and Cake & 905 & Whey Cheese \\
\hline 518 & Apple juice & 666 & Chocolate Prsnes & 907 & Processed Cheese \\
\hline 521 & Pears & 667 & Tea & 909 & Prod.of Nat.Milk Constit \\
\hline 526 & Apricots & 677 & Hops & 919 & Cattle hides \\
\hline 527 & Dry Apricots & 687 & Pepper (Piper spp.) & 920 & Hides Wet Salted Cattle \\
\hline 530 & Sour cherries & 689 & Chillies and peppers, dry & 921 & Hidesdry S.Cattle \\
\hline 531 & Cherries & 692 & Vanilla & 976 & Sheep \\
\hline 534 & Peaches and nectarines & 693 & Cinnamon (canella) & 977 & Sheep meat \\
\hline
\end{tabular}


Table B2. (continue...).

\begin{tabular}{|c|l||c|l||c|l|}
\hline id & \multicolumn{1}{|c|}{ FAO Products } & id & \multicolumn{1}{|c|}{ FAO Products } & id & \multicolumn{1}{|c|}{ FAO Products } \\
\hline 978 & Offals of Sheep,Edible & 1037 & Fat of Pigs & 1096 & Horses \\
984 & Cheese of Sheep Milk & 1039 & Bacon and Ham & 1097 & Horse meat \\
998 & Skins Nes Sheep & 1041 & Sausages of Pig Meat & 1100 & Hair of Horses \\
999 & Skins With Wool Sheep & 1042 & Prep of Pig Meat & 1103 & Hides Wet Salted Horses \\
1016 & Goats & 1057 & Chickens & 1104 & Hides Dry Slt Horses \\
1017 & Goat meat & 1062 & Hen eggs, in shell & 1105 & Hides Unsp Horse \\
1018 & Offals of Goats, Edible & 1063 & Eggs Liquid & 1107 & Asses \\
1021 & Cheese of Goat Mlk & 1064 & Eggs Dried & 1110 & Mules \\
1025 & Goatskins & 1069 & Duck meat & 1159 & Offals other camelids \\
1034 & Pigs & 1073 & Goose, guinea fowl meat & 1187 & Cocoon Unr. and Waste \\
1035 & Pig meat & 1080 & Turkey meat & 1219 & Hair Coarse Nes \\
1036 & Offals of Pigs, Edible & 1091 & Other bird eggs,in shell & 1232 & Food Prep Nes \\
\hline
\end{tabular}

